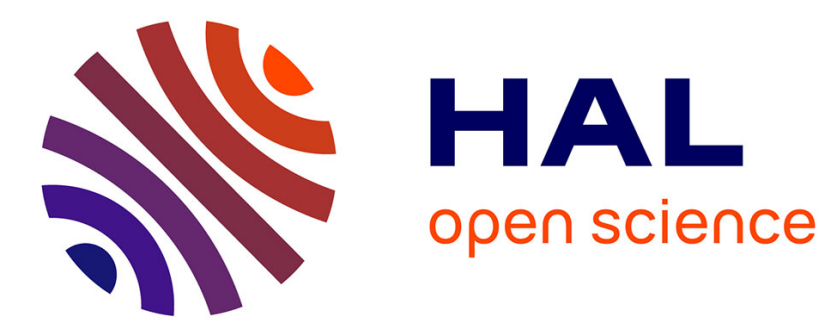

\title{
Nonlinear Fuzzy Control Based on Fuzzy Anti-Windup of VSC-HVDC Embedded into AC Grid
}

\author{
Elkhatib Kamal, Bogdan Marinescu, G. Denis
}

\section{To cite this version:}

Elkhatib Kamal, Bogdan Marinescu, G. Denis. Nonlinear Fuzzy Control Based on Fuzzy Anti-Windup of VSC-HVDC Embedded into AC Grid. 2019 IEEE PES Innovative Smart Grid Technologies Europe (ISGT-Europe), Sep 2019, Bucharest, Romania. pp.6, 10.1109/ISGTEurope.2019.8905632 . hal02512832

\section{HAL Id: hal-02512832 \\ https://hal.science/hal-02512832}

Submitted on 20 Mar 2020

HAL is a multi-disciplinary open access archive for the deposit and dissemination of scientific research documents, whether they are published or not. The documents may come from teaching and research institutions in France or abroad, or from public or private research centers.
L'archive ouverte pluridisciplinaire HAL, est destinée au dépôt et à la diffusion de documents scientifiques de niveau recherche, publiés ou non, émanant des établissements d'enseignement et de recherche français ou étrangers, des laboratoires publics ou privés. 


\title{
Nonlinear Fuzzy Control Based on Fuzzy Anti-Windup of VSC-HVDC Embedded into AC Grid
}

\author{
E. Kamal, B. Marinescu and G. Denis
}

\begin{abstract}
In this work, new robust fuzzy control based on model recovery anti-windup strategy based on robust fuzzy anti-windup is proposed for disturbances of multivariable High Voltage Direct Current (HVDC) link embedded with AC grid subject to a wide range of parameter uncertainties. Saturations on both control and the states are also taken into account. This work concentrates on the fault ride-through capability of the AC embedded HVDC system which may be exploited to improve the stability of the AC embedded HVDC system. The developed robust control scheme is demonstrated to be effective for temporary short-circuit conditions. The algorithm utilizes fuzzy systems based on "Takagi-Sugeno" fuzzy models to represent a nonlinear AC embedded HVDC system. Sufficient conditions are derived for robust stabilization in the sense of Lyapunov stability and are formulated with linear matrix inequalities to obtain controller gains and anti-windup gains. First, a nonlinear robust fuzzy controller is designed subject to a disturbance with parameter uncertainties. Next, an additional anti-windup is designed to mitigate the adverse effects due to state and the control constraints. The proposed control system is compared with alternative frameworks existing in the literature based on robust control via simulations performed with MATLAB software, to illustrate the effectiveness of the proposed method.
\end{abstract}

\section{INTRODUCTION}

$\mathbf{I}$ $\mathrm{N}$ the 1950s, with the development of mercury switches, the systems High Voltage Direct Current (HVDC) transmission are become attractive for long-distance power transmissions. Their principle can be summarized as follows: the alternative power provided by one (or more) source (s) is first transformed into a continuous power. A converter (rectifier) ensures the operation. The power then passes through a transmission line and, finally, another converter (inverter) converts this continuous power into a power alternative delivered to one or more loads [1], [2]. Recently, rapid advancement has been achieved in the field of control of VSC-HVDC systems. Firstly, Fault Ride-Through (FRT) capability [3], is a high priority consideration for any power system. Presently, many studies and works have been done both in improving transient stability and voltage regulation of the power system. HVDC converter controls have an impact on the dynamics of neighboring AC zones of the grid in which the HVDC is inserted [2]. An

E. Kamal and B. Marinescu are with ECN (Ecole Centrale Nantes)- LS2N (Laboratoire des sciences du numérique de Nantes)-DSG (team Dynamics of Smart Grids), 1, rue de la Noë, 44000 Nantes Cedex 3, France, Email: Elkhatib.ibrahim@ec-nantes.fr and Bogdan.Marinescu@ec-nantes.fr.

G. Denis is with Réseau de Transport d'Eléctricité (RTE) de France, Defense, France, Email: guillaume.denis@rte-france.com

This project is supported by the chair Automatic control and power systems of Ecole Centrale Nantes-RTE (see http://chairerte.ec-nantes.fr/home/).
HVDC embedded in an AC grid is referred to in what follows as an embedded HVDC system. In [1] control synthesis has been shown to improve critical clearing time at specific $\mathrm{AC}$ critical buses in the HVDC neighborhood. In addition, [3][8] neglect the effect of the parameter uncertainties which make the system unstable. Also, all the previous strategies [3][8] study the robust stability for HVDC without considering saturation on both control and states which cause the system unstable.

Secondly, robustness and stability control for VSC-HVDC system with uncertainties. Parameter uncertainties denote the phenomena that values of the parameters deviate from the nominal values and make the system unstable [9].

Takagi-Sugeno's fuzzy models [10]-[16] have the property of approximating any non-linear function, while dispensing with explicit models of the process. The control laws commonly used for Takagi- Sugeno fuzzy models are of the non-linear static state feedback type called PDC (Parallel Distributed Compensation) control [17]. This type of control law uses the same non-linear functions to interpolate the linear models of the TS models. The study of the stability and stabilization of these types of models uses, in the vast majority of cases, the second Lyapunov method (direct method). In almost all cases, a quadratic Lyapunov function is used. This is mainly due to the fact that it is possible to solve the conditions of stability/stabilisation. Indeed, one of the main difficulties is to be able to write these conditions in the form of LMI constraints (Linear Matrix Inequalities) [10]. LMIs, if it appears that they admit a solution, can be solved using tools from the field of convex optimization.

This work develops a new Nonlinear Robust Fuzzy Controller (NRFC) based on model recovery anti-windup strategy based on Robust Fuzzy Model Recovery Anti-windup (RFMRAW). The results of this paper support that the proposed strategy is capable of:

(i) Overcoming the problems linked with nonlinearities in [1], [2];

(ii) Fault Ride-Through (FRT) capability of the HVDC-AC, for instance, short-circuits and the control saturation which are the main drawback of the studies in [18];

(iii) Compensating for the effect of the parameter uncertainties which are neglected in [3];

(iv) Stabilization uncertain HVDC systems having restricted states and controls which are the main drawback of the study in [1]. 
We consider here the problems of stability analysis and synthesizing dynamic RFMRAW compensators for a TS fuzzy AC embedded HVDC system subject to control and state constraints, parameter uncertainties and disturbances. First, we propose a simple model of the AC embedded HVDC system. Then, the proposed strategy is designed based on RFMRAW for the AC embedded HVDC system with normbounded parametric uncertainties, disturbance, and saturation on both control and states. In addition, the proposed strategy is proved to be effective for temporary short-circuits in AC grid. The objective of paper is to establish the control laws based on PDC [17] and LMI [10] that allow stabilization HVDC systems of the VSC type. The control laws assume in this paper that the state of the system is known at any time. They have been validated in simulation and we will be able to see that the presence of the converters is a benefit for the stabilization of HVDC.

The paper is organized as follows. In Section II, the control problem is formulated. In Section III, the proposed robust fuzzy model recovery control strategy structure is developed. Stability and robustness analysis of proposed strategy are presented in Section IV. Overall VSC-HVDC link embedded with AC grid is given in Section V. Simulation results are presented in Section VI. Finally, the conclusions and future work are presented in section VII.

\section{Control Problem Formulation}

This section states the formulation of problem of input and/or state constraints with a wide range of parametric uncertainties and the effect of disturbances on the system. The global model takes following form:

$$
\begin{aligned}
\dot{x}(t)= & \sum_{i=1}^{p} \mu_{i}(q(t))\left[\left(A_{i}+\Delta A_{i}\right) x(t)\right. \\
& \left.+\left(B_{i}+\Delta B_{i}\right) \operatorname{sat}(u(t))+B_{d i} w(t)\right] \\
y(t)= & \sum_{i=1}^{p} \mu_{i}(q(t))\left[C_{i} x(t)+D_{i} \operatorname{sat}(u(t))\right]
\end{aligned}
$$

where $x(t) \in \Re^{n \times 1}, y(t) \in \Re^{g \times 1}$ and $u(t) \in \Re^{m \times 1}$ are the state, the output and the input vectors, respectively, $C_{i} \in \Re^{g \times n}$ is the system output matrix, $\Delta A_{i} \in \Re^{n \times n}$ and $\Delta B_{i} \in \Re^{n \times m}$ are the uncertainties of the constant system matrices $A_{i} \in$ $\Re^{n \times n}$ and $B_{i} \in \Re^{n \times m}$, respectively, $B_{d i} \in \Re^{n \times 1}$ is a known matrix, $w(t)$ is the disturbance vector and sat is the saturation which is given by $\operatorname{sat}(u)$ is defined by $\operatorname{sat}(u)=u_{\min }$ if $u(t) \leq u_{\min }, \operatorname{sat}(u)=u(t)$ if $u_{\max } \leq u(t) \leq u_{\min }, \operatorname{sat}(u)=$ $u_{\max }$ if $u(t) \leq u_{\max }$. In this study, the parameter uncertainties are assumed given by:

$$
\Delta A_{i}=E_{1 i} F_{i}(t) H_{1 i} \quad \Delta B_{i}=E_{2 i} F_{i}(t) H_{2 i}
$$

where $E_{1 i}, E_{2 i}, H_{1 i}$ and $H_{2 i}$ are known real constant matrices and $F_{i}(t)$ are unknown real matrices with Lebesgue measurable elements, satisfying $F_{i}(t)^{T} F_{i}(t) \leq I, i=1, \ldots, p$, where $I$ is the identity matrix. The states are also constrained as follows

$$
\gamma(M, N)=\left\{x \in \Re^{n \times 1} / M x \leq N\right\}
$$

where $M \in \Re^{h \times n}$ and $N \in \Re^{h \times 1}$ are known. The control problem formulated has both local $(\mathrm{L})$ and grid $(\mathrm{G})$ objectives:
L: Minimize the steady state error (so that the controlled output tracks its reference value). In order to force to zero the steady-state tracking errors, we add new states which corresponds to the integral action.

$G$ : The regulator should provide good FRT capability. This will improve the steady-state and transient stabilities of the AC embedded HVDC system.

\section{Proposed Robust Fuzzy CONTROL BASED ON RFMRAW}

In this section, the proposed NRFC based on RFMRAW is designed.

\section{A. Proposed NRFC}

First, the dynamic controller fuzzy rules are constructed based on the PDC [17] for the fuzzy model (1),

$$
u(t)=\sum_{j=1}^{p} \mu_{i} K_{i} x(t)
$$

where $K_{i} \in \Re^{m \times n}$ are feedback gain vectors for rule.

\section{B. Proposed RFMRAW}

After controller gains are obtained using (4), the antiwindup adapted to the fuzzy model is designed to limit the effect of actuators constraints. According to the PDC [17], dynamic equations of the modified RFMRAW are given by:

$$
\dot{x}_{d}=\sum_{j=1}^{p} \mu_{j}\left(A_{i} x_{d}+B_{i} \varphi\right), \quad \sigma=\sum_{j=1}^{p} \mu_{j}\left(G_{d i} x_{d}+L_{d i} \varphi\right)
$$

where $x_{d}(t)$ is the RFMRAWstate vector, $G_{d i}$ and $L_{d i}$ are the compensation gains and $\varphi=\operatorname{sat}(u)-u(t)$.

Finally, based on (4) and (5), the NRFC is obtained from:

$$
u(t)=\left[\begin{array}{ll}
\sum_{j=1}^{p} \mu_{j} K_{i} & I
\end{array}\right]\left[\begin{array}{l}
x(t) \\
\sigma(t)
\end{array}\right]
$$

\section{Stability And Robustness Analysis of The PROPOSED STRATEGY}

Stabilization of the system (1) is studied in two cases: first in the absence of RFMRAW to calculate the controller gains $K_{i}$ in (4), and second in presence of the RFMRAW to calculate the proposed controller as follows.

\section{A. Dynamics of Closed-Loop System without anti-windup}

From (1) and (4), the closed loop system dynamics is given by:

$$
\begin{aligned}
\dot{x}(t)= & \sum_{j=1}^{p} \mu_{j}\left[\left(A_{i}+B_{i} K_{i}\right) x(t)+\left(E_{1 i} F_{i}(t) H_{1 i}\right.\right. \\
+ & \left.\left.E_{2 i} F_{i}(t) H_{2 i} K_{i}\right) x(t)+B_{d i} w(t)\right] \\
y(t)= & \sum_{j=1}^{p} \mu_{j}\left[C_{i} x(t)+D_{i} \operatorname{sat}(u(t))\right]
\end{aligned}
$$


The main results are summarized in the following Theorem:

Theorem 1: Any equilibrium point of an uncertain fuzzy control system as given by (7) subject to the constrained states (3) and control inputs, with disturbances and parameter uncertainties is asymptotically stable in the whole domain by the controller (6), if the controller gains are set to $K_{i}=O_{i} Z_{i}^{-1}$, and there exists a positive definite symmetric matrix $P_{i}=Z_{i}^{-1}$ and scalars $\iota, \delta$ and $\beta_{i}$, such that the following LMIs are satisfied,

$$
\begin{gathered}
{\left[\begin{array}{cc}
A_{i} Z_{i}+Z_{i} A_{i}^{T}+\left(B_{i} O_{i}\right)+\left(B_{i} O_{i}\right)^{T}+\delta E_{i} E_{i}^{T}+\frac{1}{\delta} B_{d i} B_{d i}^{T} \\
+Z_{i} \delta & Z_{i} H_{1 i}{ }^{T}+O_{i} H_{2 i}{ }^{T} \\
H_{1 i} Z_{i}+H_{2 i} O_{i} & -\delta I
\end{array}\right]} \\
{\left[\begin{array}{cc}
\iota \beta_{j i} N_{j i}-M_{j i} Z_{i} M_{j i}^{T} & \beta_{j i} \\
\beta_{j i} & 1
\end{array}\right] \geq 0, \quad\left[\begin{array}{cc}
1 & O_{l i} \\
O_{l i}^{T} & Z_{i}
\end{array}\right] \geq 0}
\end{gathered}
$$

where, $1 \leq l \leq c, 1 \leq j \leq m, O_{l}, N_{l i}$ and $M_{l i}$ are the $l^{t h}$ row of $O_{i}, N_{i}$ and $M_{i}$, respectively and $\iota$ is a constant.

Proof: The closed-loop system in the absence of RFMRAW. (7) should be obtained first. Based on [10], the proof and the controller gains $K_{i}$ are obtained.

\section{B. Dynamics of Closed-Loop System in Presence of RFMRAW Compensator}

To design the RFMRAW gains $\left(G_{d i}\right.$ and $\left.L_{d i}\right)$ in (5) the closed-loop system with RFMRAW should be obtained first. Let $\varphi=\operatorname{sat}(u)-u(t) . K_{i}$ are obtained using Theorem 1 . From (1) and (6), the closed loop system in the presence of RFMRAW compensator is given by:

$$
\begin{aligned}
& \dot{x}=\sum_{j=1}^{p} \mu_{j}\left[\bar{A}_{i} x+B_{i} \varphi\right], \quad y=\sum_{j=1}^{p} \mu_{j}\left[\bar{C}_{i} x+D_{i} \varphi\right] \\
& y_{z}=\sum_{j=1}^{p} \mu_{j}\left[\bar{C}_{z i} x+D_{z i} \varphi\right]
\end{aligned}
$$

where $\bar{A}_{i}=A_{i}+B_{i} K_{i}, \bar{C}_{i}=C_{i}+D_{i} K_{i}, \bar{C}_{i}=C_{z i}+D_{z i} K_{i}$, $y(t) \in \Re^{g_{y} \times 1}$ are the measurement output and $y_{z}(t) \in \Re^{g_{z} \times 1}$ is the performance output.

The main results are summarized in the following Theorem:

Theorem 2: If there exist a symmetric positive definite matrix, $Q$, another matrix, $Y$, and a positive scalar, $\varrho$, such that the following conditions hold:

$$
\begin{gathered}
{\left[\begin{array}{cccc}
\Gamma_{1} & * & * & * \\
B_{i}^{T} & -I & * & * \\
\bar{C}_{z i} Q-D_{z i} Y & D_{z i} & -\bar{\varrho} I & * \\
\Gamma_{2} & -\bar{L}_{d i} & D_{z i}^{T}-\bar{L}_{d i} D_{z i}^{T} & \Gamma_{3}
\end{array}\right]} \\
\left(\bar{A}_{i}+B_{i} \bar{G}_{d i}\right) Q+Q\left(\bar{A}_{i}+B_{i} \bar{G}_{d i}\right)^{T}-2 Q \lambda \leq 0 \\
Q \geq 0
\end{gathered}
$$

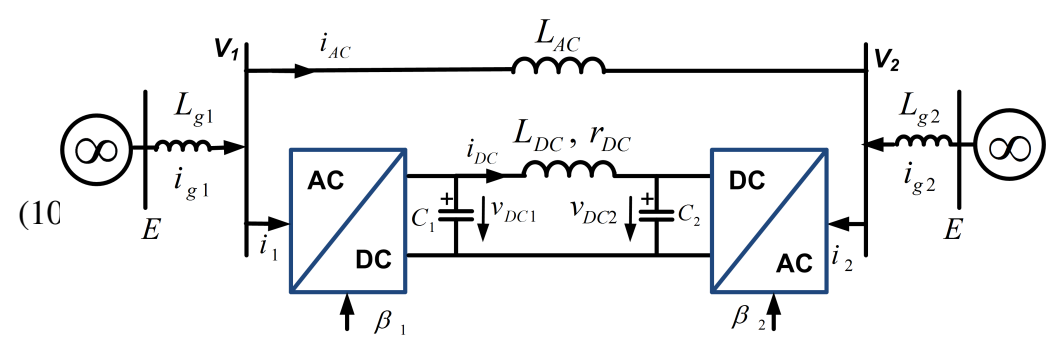

with $\Gamma_{1}=\bar{A}_{i} Q+\bar{A}_{i}^{T}+B_{i} Y+\left(B_{i} Y\right)^{T}$, $\Gamma_{2}=\bar{G}_{d i} Q-Y-\bar{L}_{d i} B_{i}^{T}$ and $\Gamma_{3}=-\bar{L}_{d i}+\bar{L}_{d i}^{T}-2 I$ and $*$ is the conjugate transposed, then considered equilibrium point of the closed-loop system (1) and (9) can be made asymptotically stable in the whole domain by the controller (6) and the anti-windup (5) with the gains set to $G_{d i}=-\left(I-\bar{L}_{d i}\right)^{-1} \bar{G}_{d i}$ and $L_{d i}=-\left(I-\bar{L}_{d i}\right)^{-1} \bar{L}_{d i}$.

Proof: In [19], several other algorithms are expressed, in particular using Lyapunov based procedure. By the same analysis procedure in the Theorem 1 and using the Schur complement method [20] and based on the analysis procedure [21], we can obtain (10) of Theorem 2.

\section{Overall VSC-HVDC Link EMBEDDED IN AC GRID MODELING AND DESCRIPTION}

This section contains the dynamic equations describing the AC embedded HVDC system. The example in Fig. 1 was chosen to illustrate the case of a VSC-HVDC link embedded in AC grid. It is simple enough to follow directly the analytic modelling and capture the significant points, the parallel AC line ensures AC interactions between the two HVDC terminals while the two lines towards the infinite buses model the shortcircuit power at each terminal. The average model of the converter proposed in [8] is used in this paper. The dynamic equations in $d q$ coordinates of the AC embedded HVDC system in Figure 1 are [7] :

$$
\begin{aligned}
& \frac{d i_{1 d}^{\infty}}{d t}=\omega i_{1 q}^{\infty}+\frac{1}{L_{g 1}} E-\frac{1}{2}\left(\frac{1}{L_{g 1}}+\frac{1}{L_{A C}}\right) v_{D C 1} \beta_{1 d}^{\infty} \\
& +\frac{1}{2} \frac{1}{L_{A C}} v_{D C 2} \beta_{2 d}^{\infty} \\
& \frac{d i_{1 q}^{\infty}}{d t}=-\omega i_{1 d}^{\infty}-\frac{1}{2}\left(\frac{1}{L_{g 1}}+\frac{1}{L_{A C}}\right) v_{D C 1} \beta_{1 q}^{\infty}+\frac{1}{2} \frac{1}{L_{A C}} v_{D C 2} \beta_{2 q}^{\infty} \\
& \frac{d i_{2 d}^{\infty}}{d t}=\omega i_{2 q}^{\infty}+\frac{1}{L_{g 2}} E-\frac{1}{2}\left(\frac{1}{L_{g 2}}+\frac{1}{L_{A C}}\right) v_{D C 2} \beta_{2 d}^{\infty} \\
& +\frac{1}{2} \frac{1}{L_{A C}} v_{D C 1} \beta_{1 d}^{\infty} \\
& \frac{d i_{2 q}^{\infty}}{d t}=-\omega i_{2 d}^{\infty}-\frac{1}{2}\left(\frac{1}{L_{g 2}}+\frac{1}{L_{A C}}\right) v_{D C 2} \beta_{2 q}^{\infty}+\frac{1}{2} \frac{1}{L_{A C}} v_{D C 1} \beta_{1 q}^{\infty} \\
& \frac{d v_{D C 1}}{d t}=\frac{3}{2 C_{1}}\left(i_{1 d}^{\infty} \beta_{1 d}^{\infty}+i_{1 q}^{\infty} \beta_{1 q}^{\infty}\right)-\frac{2}{C_{1}} i_{D C} \\
& \frac{d v_{D C 2}}{d t}=\frac{3}{2 C_{2}}\left(i_{2 d}^{\infty} \beta_{2 d}^{\infty}+i_{2 q}^{\infty} \beta_{2 q}^{\infty}\right)+\frac{2}{C_{2}} i_{D C} \\
& \frac{d i_{D C}}{d t}=\frac{1}{2 L_{D C}} v_{D C 1}-\frac{1}{2 L_{D C}} v_{D C 2}-\frac{r_{D C}}{L_{D C}} i_{D C}
\end{aligned}
$$

where, $i_{1 d}^{\infty}$ and $i_{1 q}^{\infty}, i_{2 d}^{\infty}, i_{2 q}^{\infty}, \beta_{1 d}^{\infty}, \beta_{1 q}^{\infty}, i_{D C} v_{D C 1}, \beta_{2 d}^{\infty}$, $\beta_{2 q}^{\infty}, v_{D C 2}$ are variables for VSC on the left and right sides, respectively, $L_{g 1}, L_{g 2}, L_{A C}, r_{D C}, L_{D C}, C_{1}, C_{2}$, $E$ and $\omega$ are constants. $P_{2}, Q_{1}, Q_{2}$ are the active and $\left.\frac{1}{2}\left(\beta_{1 q}^{\infty} v_{D C 1} i_{1 d}^{\infty}\right)\right), P_{2}=\frac{3}{2}\left(\frac{1}{2}\left(\beta_{2 d}^{\infty} v_{D C 2} i_{2 d}^{\infty}\right)+\frac{1}{2}\left(\beta_{2 q}^{\infty} v_{D C 2} i_{2 q}^{\infty}\right)\right)$, $Q_{2}=\frac{3}{2}\left(\frac{1}{2}\left(\beta_{2 d}^{\infty} v_{D C 2} i_{2 q}^{\infty}\right)-\frac{1}{2}\left(\beta_{2 q}^{\infty} v_{D C 2} i_{2 d}^{\infty}\right)\right)$,

Fig. 1. HVDC power structure control model.

\section{Simulations Results and Discussion}

Three Matlab simulations and discussions on the model proposed in Section IV are presented. reactive powers, respectively: $Q_{1}=\frac{3}{2}\left(\frac{1}{2}\left(\beta_{1 d}^{\infty} v_{D C 1} i_{1 q}^{\infty}\right)-\right.$ 
Simulation 1: Proposed Strategy Validation Subject to $40 \%$ of Parameter Uncertainties, 35\% of Disturbance and Saturation on Both States and Control

The objective here is to conceive the saturation on both states and the control for AC embedded HVDC system model. In this paper, we consider that the current variables $\left(x_{1}\right.$, $x_{2}, x_{3}, x_{4}$ ) are constrained based on (3) as $-2000 A m p \leq$ $x_{1}, x_{2}, x_{3}, x_{4} \leq 2000 A m p$. Also, the control inputs $(-1 \leq$ $\left.u_{1}, u_{2}, u_{3}, u_{4} \leq 1\right)$ are considered constrained.

The uncertainties of $40 \%$ are considered in the DC link resistance $\left(r_{D C}\right)$ and $\mathrm{AC}$ grid inductances $\left(L_{g 1}, L_{g 2}\right)$ and additive disturbance about $35 \%$. Therefore, additive disturbance is given by $B_{d i} \operatorname{sign}(\sin (0.3 t))$, where the additive disturbance matrix is $B_{d i}=\left[\begin{array}{lllllll}0.35 & 0.35 & 0.35 & 0.35 & 0.35 & 0.35 & 0.35\end{array}\right]^{T}$ $(\mathrm{i}=1,2, \ldots, 8)$.

Figure 2 shows the step response of the DC voltage ( $V_{D C 1}$ $[\mathrm{KV}])$. Reactive powers $\left(Q_{1}[\mathrm{MVA}]\right.$ and $Q_{2}$ [MVA]) are given in Figures 3 and 5, respectively. Figure 4 illustrates the active power $\left(P_{2}[\mathrm{MW}]\right)$.

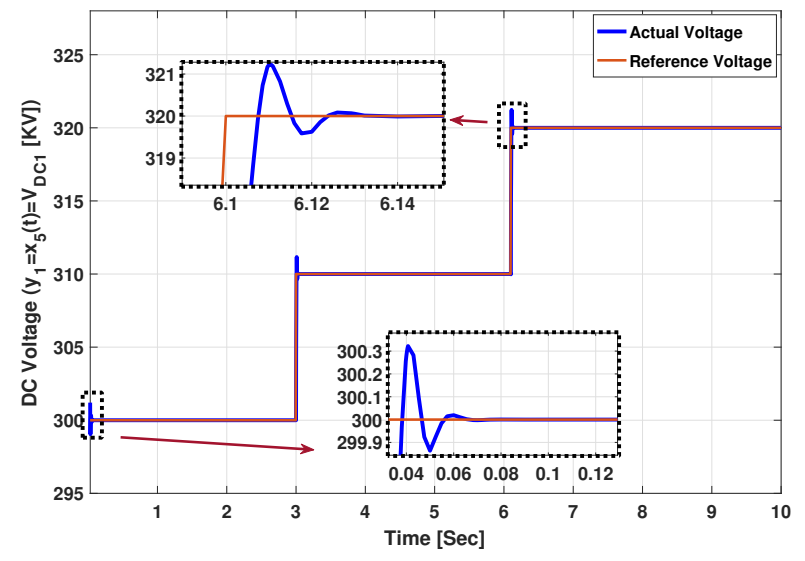

Fig. 2. Time response of the DC voltage $\left(y_{1}=x_{5}=V_{D C 1}[\mathrm{KV}]\right)$.

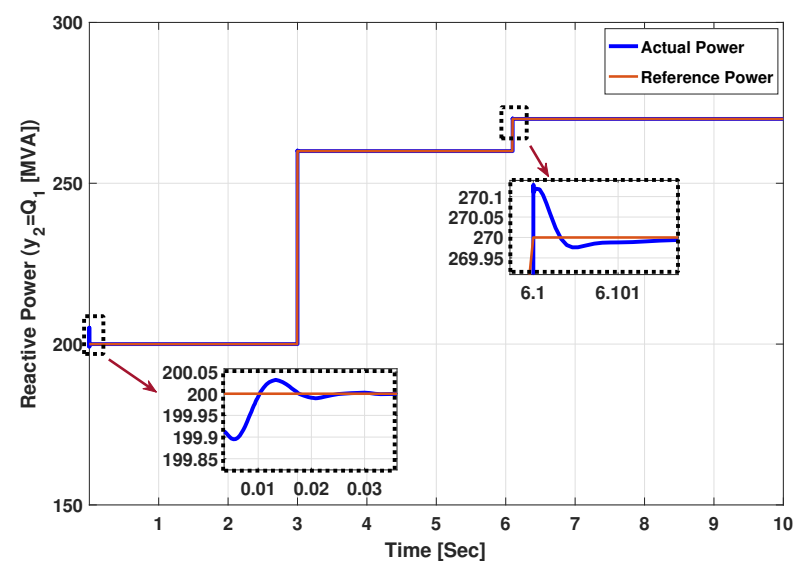

Fig. 3. Time response of the reactive power $\left(y_{2}=Q_{1}[\mathrm{MVA}]\right)$.

From simulation 1 results, it cab be seen that the effectiveness of the proposed control approach.

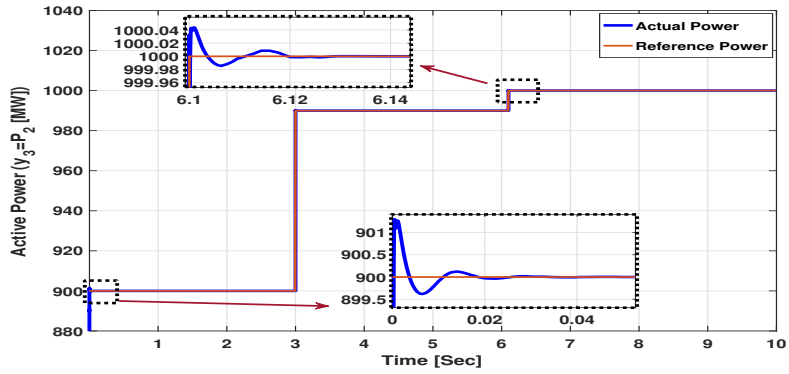

Fig. 4. Time response of the active power $\left(y_{3}=P_{2}[\mathrm{MW}]\right)$.

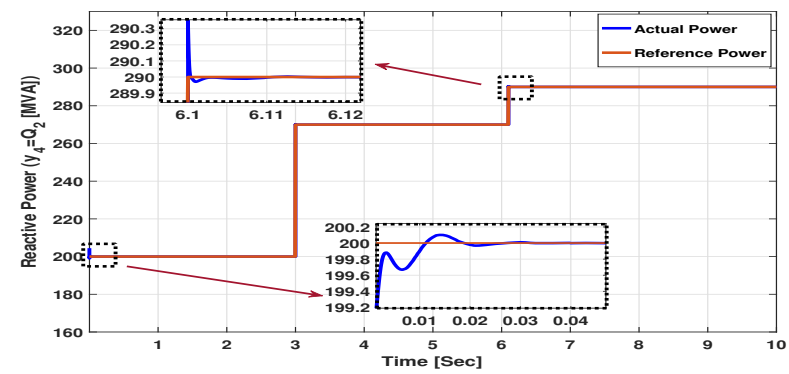

Fig. 5. Time response of the reactive power $\left(y_{4}=Q_{2}[\mathrm{MVA}]\right)$.

Simulation 2: Proposed Overall Control Architecture to Illustrate the Robustness Compared to other Strategy

Simulation 2 demonstrates the effectiveness and robustness of the proposed overall control architecture proposed strategy compared with the RC strategy [10] methods already existing in the literature. For simulation runs, the same parameter and constraint conditions as in the preceding section are considered. The elements $\Delta A_{i}$ and $\Delta B_{i}$ achieve values within $42 \%$ of their nominal values corresponding to system parameter variations in $\left(L_{g 1}\right.$ and $\left.L_{g 2}, r_{D C}\right)$. Figure 6 shows the time responses of the DC voltage $\left(V_{D C 1}[\mathrm{KV}]\right)$ for the proposed strategy (left) and Robust Controller (RC) [10] (right) strategy, respectively.
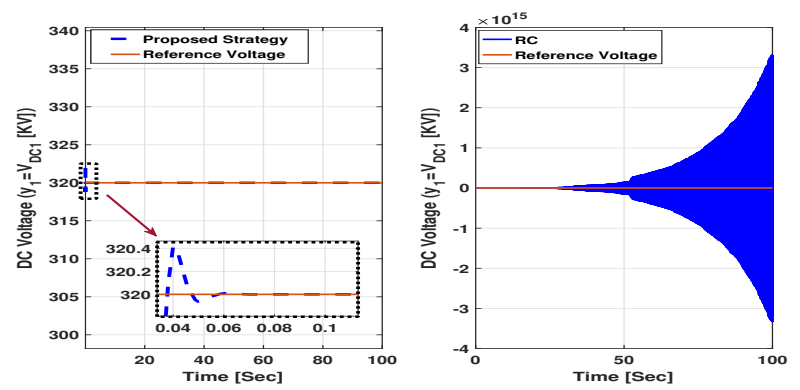

Fig. 6. Time response of the DC voltage $\left(y_{1}=V_{D C 1}[\mathrm{KV}]\right)$ for the proposed strategy (left) and RC strategy (right).

It can be seen that the proposed strategy gives a good tracking performance while the RC strategy algorithm [10] cannot give a good robustness and leads to system instability. 


\section{Simulation 3: FRT Capability Validation}

In order to validate the FRT capability, a short-circuit is applied at $t_{s}=5 \mathrm{sec}$ in the middle of the AC parallel line and cleared at $t_{c}=5.1 \mathrm{Sec}$. In simulation 3 , the maximum level of uncertainty is assumed only for inductance, $L_{g 1}$ and reference variation in the reactive power is considered. Figure 7 shows the reactive power, $Q_{1}[\mathrm{MVA}]$, response on left AC side of VSC-HVDC. It is observed from the results that the proposed algorithm gives good robustness in this case.

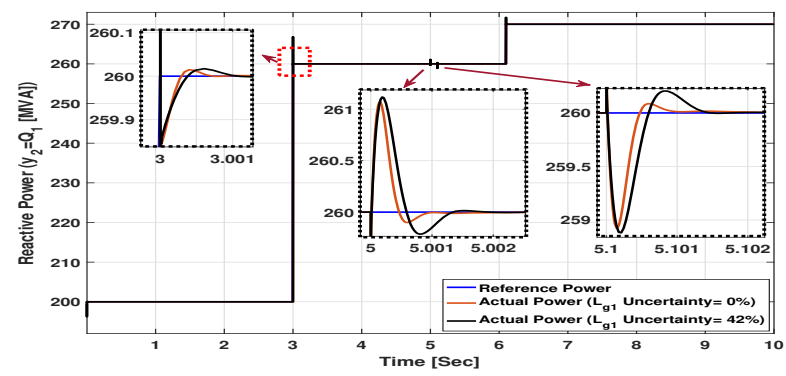

Fig. 7. Reactive power behavior ( $\left.y_{2}=Q_{1}[\mathrm{MVA}]\right)$ on left AC side of VSC-HVDC considering inductance $\left(L_{g 1}\right)$ with and without uncertainty and $100 \mathrm{~ms}$ short-circuit at $t_{s}=5 \mathrm{sec}$ and reference variation in $Q_{1}$.

The simulations results imply that the proposed strategy can fully control the plant whereas previous algorithms considered [10] failed to provide adequate responses and lead to system instability.

\section{CONCLUSION}

This work presented a Robust Fuzzy Control Based on Model Recovery Anti-Windup Strategy in presence of parameter uncertainties, disturbances, and saturations on both states and control for a nonlinear VSC- HVDC link embedded in AC grid. Sufficient conditions for robust stabilization of the TS fuzzy model were derived in a LMI formalism. To implement the proposed strategy, a nonlinear Robust Fuzzy Controller subject to disturbance and parameters uncertainties is combined with an additional Robust Fuzzy Model Recovery Anti-windup to compensate for the effects of saturation on both states and the control. The overall proposed strategy is tested and compared with alternative frameworks existing in the literature in order to demonstrate the advantages of the proposed methodology. The obtained results confirm that, using the proposed approach: (i) the strategy can be easily implemented in real time because it is simple and implemented by only 8 fuzzy rules; (ii) it compensates the effect of the parameter uncertainties up to $42 \%$ (which is a higher level compared with [10]) and disturbance up to 40\%; (iii) VSCHVDC link embedded with AC grid with constraints on both states and the control is stable. Also, a good fault ride-through capability of the closed-loop system is demonstrated. This work compels improvements of the transient stability margin in the AC grid neighborhood which will be fully analyzed in subsequent work. In addition, the hypothesis of direct access to $d$ and $q$ components (ideal Phase-Locked-Loop (PLL)) will be no longer used as an estimator will be synthesized for this in conjuction with the controller.

\section{REFERENCES}

[1] L. Arioua and B. Marinescu, Multivariable control with grid objectives of an HVDC link embedded in a large-scale AC grid, Int. J. Electr. Power Energy Syst., vol.72, pp. 99-108, 2015.

[2] L. Arioua, B. Marinescu and E. Monmasson, Control of high voltage direct current links with overall large-scale grid objectives, IET Gener. Transm. Distrib., vol. 8, pp. 945-956, 2014

[3] H. D. Chiang, Direct Methods for Stability Analysis of Electric Power Systems, Wiley 2011.

[4] S. Corsi, A. Danelli, and M. Pozzi al. (2002). Emergency-stability controls through HVDC links. IEEE Conference: Power Engineering Society Summer Meeting, vol.2, pp. 774 -779, 2002.

[5] J. Y. Jiang-Hiker, H. Duchen, K. Lindkn and M. Hyttinen, Improvement of subsynchronous torsional damping using VSC HVDC, Power System Technology, Proceedings. International Conference on Power System Technology, pp. 998- 1003, 2002.

[6] B. Singh, B. K. Panigrahi and D. M. Mohan, Voltage Regulation and Power Flow Control of VSC Based HVDC System, International Conference on Power Electronic, Drives and Energy Systems, 12-15 Dec. 2006.

[7] L. Arioua and B. Marinescu, Robust grid-oriented control of high voltage DC links embedded in an AC transmission system, Int. J. Robust Nonlinear Control, vol. 26, pp.1944-1961, 2016.

[8] I. Munteanu, B. Marinescu and F. Xavier, Analysis of the interactions between close HVDC links inserted in an AC grid, Proc. of the 2017 IEEE Power \& Energy Society General Meeting, Chicago, Illinois, USA, July 2017, pp. 1-5.

[9] E. Kamal, A. Aitouche, R. Ghorbani and M. Bayart. Fuzzy Scheduler Fault Tolerant Control for Wind Energy Conversion Systems, IEEE Transactions on Control Systems Technology, vol. 22, no. 1,pp. 119-131 2014.

[10] E. Kamal, M. Koutb, A. A. Sobaih and B. Abozalam, An intelligent maximum power extraction algorithm for hybrid wind-diesel-storage system, Int. J. Electr. Power Energy Syst., vol. 32, no. 3, p. 170-177, 2010 .

[11] E. Kamal and L. Adouane, Hierarchical Energy Optimization Strategy and its Integrated Reliable Battery Fault Management for HydraulicElectric Hybrid Vehicle, IEEE Transactions on Vehicular Technology, vol. 67, no. 5, pp. 3740-3754, 2018

[12] E. Kamal, A. Aitouche, and D. Abbes. Robust fuzzy scheduler fault tolerant control of wind energy systems subject to sensor and actuator faults, International Journal of Electrical Power and Energy Systems, vol. 55, no.1, pp. 402-419, 2014

[13] E. Kamal, A. Aitouche. Fuzzy Fault-Tolerant Control of Wind-Diesel Hybrid Systems Subject to Sensor Faults, IEEE Transactions on Sustainable Energy, vol. 4, no 4, pp. 857-866, 2013.

[14] E. Kamal, A. Aitouche. Robust Scheduler Fuzzy Controller of DFIG Wind Energy Systems, IEEE Transactions on Sustainable Energy, vol. 4, no 3, pp. 706-715, 2013.

[15] E. Kamal, A. Aitouche, R. Ghorbani and M. Bayart. Robust Nonlinear Control of Wind Energy Conversion Systems, International Journal of Electrical Power and Energy Systems, 44, no.1, pp. 202-209, Jan. 2013.

[16] E.Kamal, A. Aitouche, R. Ghorbani and M. Bayart. Robust Fuzzy Fault Tolerant Control of Wind Energy Conversion Systems Subject to Sensor Faults, IEEE Transactions on Sustainable Energy, vol. 3, no 2, pp. 231241, 2012.

[17] E. Kamal and A. Aitouche, Robust fault tolerant control of DFIG wind energy systems with unknown inputs, Renewable Energy, vol.56, pp. 2 $15,2013$.

[18] J. Thomas, S. Poullain and A. Benchaib, Analysis of a robust DC-bus voltage control system for a VSC transmission scheme. In: IEE Proceedings of the 7th international conference on AC-DC power transmission, London, UK, pp. 119-24, November 2001.

[19] L. Zaccariana and A. R. Teel, A common framework for anti-windup, bumpless transfer and reliable designs, Automatica, vol. 38, pp. 17351744, 2002.

[20] F. Zhang, The Schur Complement and Its Applications, SBN: 978-0387-24271-2, 2005.

[21] S. Tarbouriech, G. Garcia, J. M. Gomes da Silva and I. Queinnec, Stability and Stabilization of Linear Systems with Saturating Actuators, ISBN 978-0-85729-941-3, 2011. 